\title{
Global Data Toolset (GDT)
}

\section{Rocky Mountain Geographic Science Center}

According to the United Nations Environment Programme World Conservation Monitoring Centre (UNEP-WCMC) approximately 60 percent of the data contained in the World Database on Protected Areas (WDPA) has missing or incomplete boundary information. As a result, global analyses based on the WDPA can be inaccurate, and professionals responsible for natural resource planning and priority setting must rely on incomplete geospatial data sets.

To begin to address this problem the World Data Center for Biodiversity and Ecology, in cooperation with the U. S. Geological Survey (USGS) Rocky Mountain Geographic Science Center (RMGSC), the National Biological Information Infrastructure (NBII), the Global Earth Observation System, and the InterAmerican Biodiversity Information Network

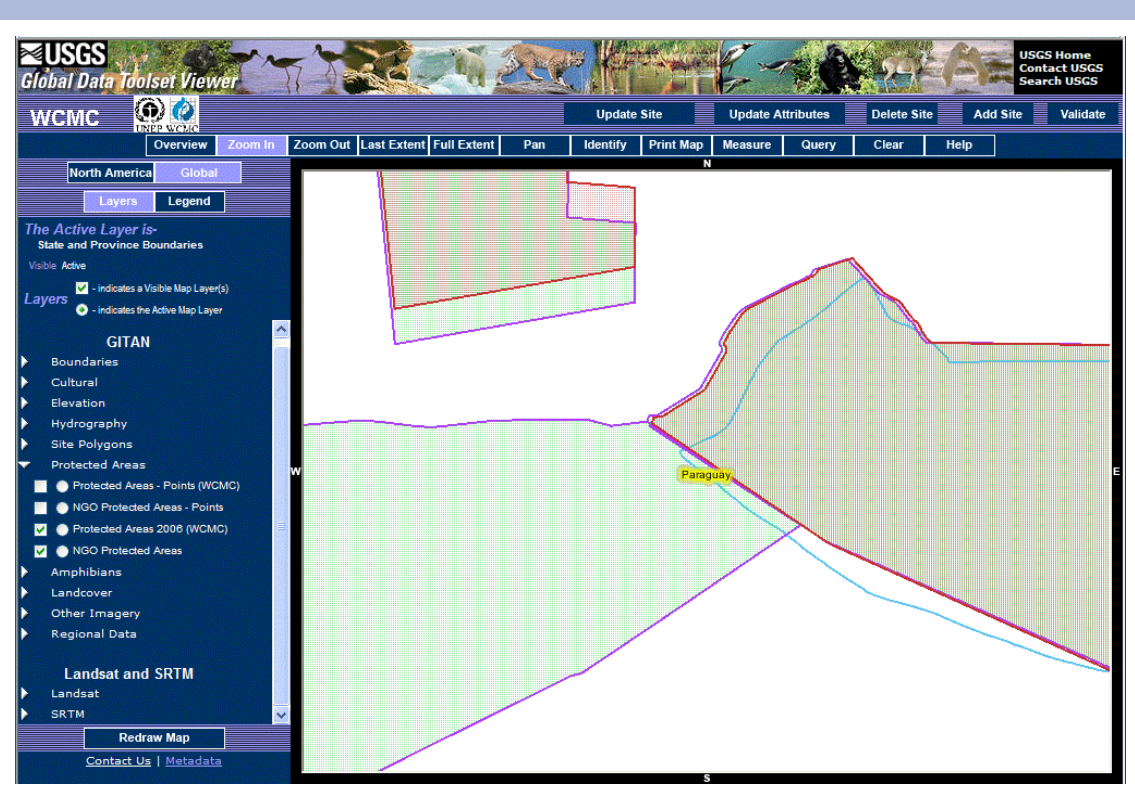

Examples of Protected Area data available from various sources. (IABIN) sponsored a Protected Area (PA)

workshop in Asuncion, Paraguay, in November 2007. The primary goal of this workshop was to train representatives from eight South American countries on the use of the Global Data Toolset (GDT) for reviewing and editing PA data. Use of the GDT will allow PA experts to compare their national data to other data sets, including non-governmental organization (NGO) and WCMC data, in order to highlight inaccuracies or gaps in the data, and then to apply any needed edits, especially in the delineation of the PA boundaries. In addition, familiarizing the participants with the web-enabled GDT will allow them to maintain and improve their data after the workshop. Once data edits have been completed the GDT will also allow the country authorities to perform any required review and validation processing. Once validated, the data can be used to update the global WDPA and IABIN databases, which will enhance analysis on global and regional levels.

\section{Overview}

One of the key goals of the USGS Geography Discipline is to assess the Nation's land resources at a range of spatial and temporal scales to understand the rates, causes, and consequences of landscape change over time. Quick and easy access to a common set of data and tools will significantly improve scientists' ability to address these types of key questions about global, national, and regional land cover usage and its potential impacts. The USGS Rocky Mountain
Geographic Science Center has developed the Global Data Toolset (GDT) to support these needs. The core objective of the GDT is to provide a web-enabled ecoregional spatial framework by providing access to a wide range of data from the global to regional scale, as well as the tools needed to answer complex questions about the effects of humans on the environment.

\section{GDT Functionality}

All of the web-enabled tools required to load and manage a rich geospatial database and perform advanced editing and delivery of data is contained in the GDT. This includes access to a publicly available application that contains basic data viewing and access functionality. This viewer also allows users to switch between a North American or Global view of the underlying database, allowing quick and easy access for both global and regional activities. This public application also includes map navigation (zoom and pan), attribute identification, map printing, metadata access, and help. 
The GDT password protected application contains more advanced functionality and access to additional scientific data. It also allows access to web-enabled data management tools that allow data owners to perform data update, review, and validation tasks against their specific data layers. Pilots are currently underway with the World Conservation Monitoring Centre (Protected Areas) to exploit these more advanced data management capabilities. The additional functionality provided by these tools allows an editor to add feature polygons by digitizing an area on the screen, uploading a polygon shapefile, or copying a polygon from another layer (WCMC, NGO, or PAD). Editors can also delete or update spatial data and update the attributes associated with a particular feature. Advanced feature query and display capabilities are also included to allow for the easy review and acceptance (that is, validation) of edited data.

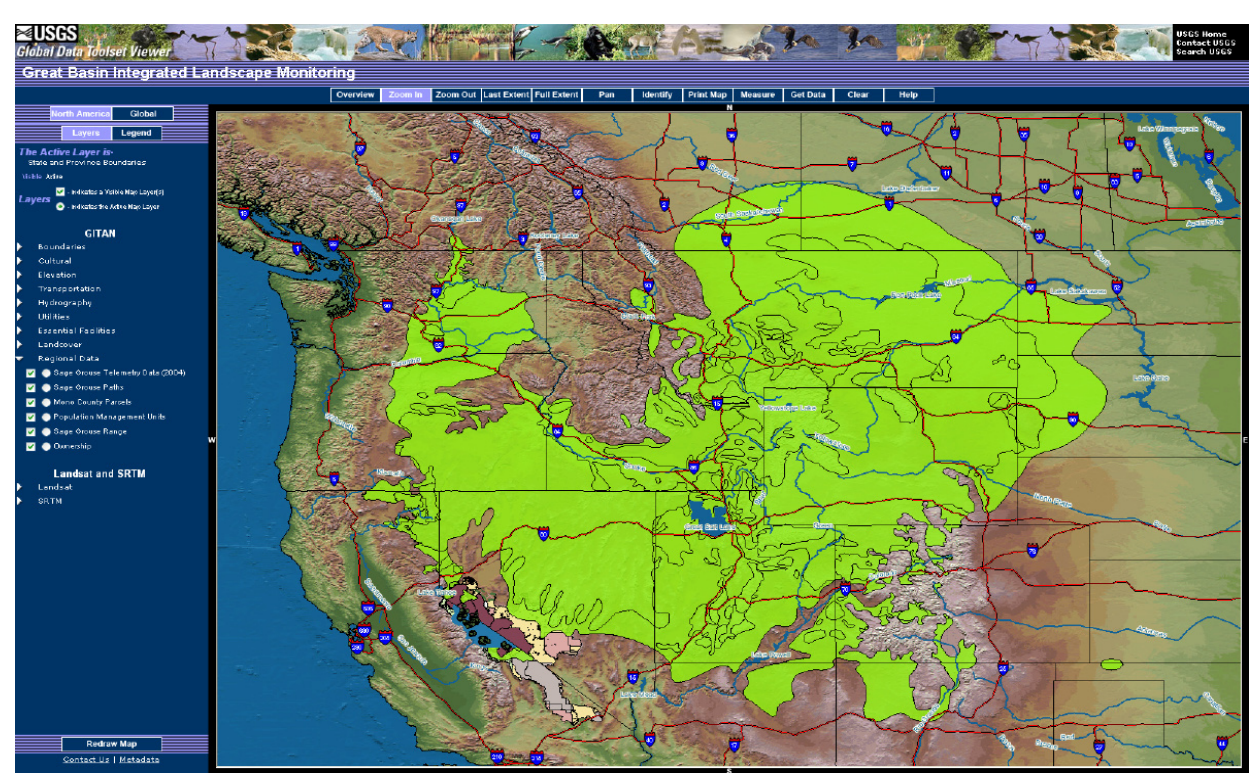

Example of a Regional Study Application
This powerful password protected application is controlled by a multilayered access system that supports different types of user accounts including: guests (data viewing), editors (data editing), and masters (data validation and access control). The easy to use account management system allows for the web-based addition, deletion, and editing of system accounts. The first step in the account process is the establishment of master accounts for each identified category of users/data (for example, Birdlife International). Once master accounts have been established, the users of these accounts are allowed complete access to both the account management system and the associated data layers. For instance, master account owners can easily add/delete/update other user accounts, and they are the only users allowed to "validate" associated data (that is, accept previously applied feature edits). Users with editor access are allowed to edit the data features associated with a particular category of users. Finally, users granted guest accounts are allowed access to only the simple data display and query tools.

This capability for multi-layered data access allows GDT to seamlessly support the full-range of users from the general public, who need to perform simple data viewing and querying tasks, to specific organizations tasked with data editing, update, and validation requirements.

\section{GDT Data}

A wide variety of geospatial data is contained in the GDT including global

data for protected areas, ecoregions, amphibian habitats, biodiversity hotspots, high biodiversity wilderness areas, hydrography, landcover, elevation, and population. This data was collected from various organizations including the IUCN-World Conservation Union, Conservation International, the World Wildlife Fund, and the World Conservation Monitoring Centre, as well as from several non-governmental agencies including the Atlas de Costa Rica, Guyra Paraguay, the National Marine Protected Areas Center, The Nature Conservancy, U.N. World Heritage Sites (UNESCO), and World Resources Institute.
Scientific data included in the password protected application includes the amphibian habitats from the Global Amphibian Assessment (GAA) program, coordinated by the IUCN-World Conservation Union, Conservation International, and NatureServe. This data contains a comprehensive assessment of the conservation status of the world's 5,743 known species of frogs, toads, salamanders, and caecilians. Additional amphibian data includes point data from the Global Biodiversity Information Facility (GBIF).

\section{Summary}

The GDT combines access to geospatial databases and analytical tools into a single web-accessible system. This combination of quick and easy access to a common set of data and sophisticated tools can significantly improve scientists' ability to both address and answer key questions about global, national, and regional land cover usage and its potential impacts. In addition, the advanced editing capability will allow users responsible for natural resource planning to easily update their geospatial datasets. Regional studies can be easily added allowing for a fast dissemination of data to those in the scientific community responsible for analysis of the data.

\section{Contacts}

Jill Cress, Computer Scientist

United States Geological Survey

Rocky Mountain Geographic Science

Center

Denver Federal Center

Lakewood, CO 80225

e-mail: jjcress@usgs.gov

Jodi Riegle, Computer Scientist

United States Geological Survey

Rocky Mountain Geographic Science

Center

Denver Federal Center

Lakewood, CO 80225

e-mail: jlriegle@usgs.gov

URL: http://rmgsc.cr.usgs.gov/gitan 